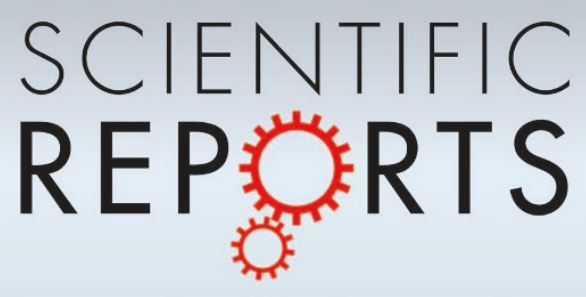

OPEN

SUBJECT AREAS:

FUEL CELLS

COLLOIDS

MOLECULAR SELF-ASSEMBLY

SELF-ASSEMBLY

Received

18 June 2013

Accepted

15 August 2013

Published

2 September 2013

Correspondence and requests for materials should be addressed to H.X. (xuh@upc.edu.cn) or J.L. (j.lu@

manchester.ac.uk)

\section{Short peptide-directed synthesis of} one-dimensional platinum nanostructures with controllable morphologies

\author{
Kai Tao', Jiqian Wang' ${ }^{1}$, Yanpeng Li' ${ }^{1}$, Daohong Xia' ${ }^{1}$, Honghong Shan' ${ }^{1}$ Hai Xu' \& Jian R. Lu'
}

\begin{abstract}
'State Key Laboratory of Heavy Oil Processing and Center for Bioengineering and Biotechnology, China University of Petroleum (East China), 66 Changjiang West Road, Qingdao 266580, China, ${ }^{2}$ Biological Physics Group, School of Physics and Astronomy, the University of Manchester, Manchester M13 9PL, United Kingdom.
\end{abstract}

Although one dimensional (1D) Pt nanostructures with well-defined sizes and shapes have fascinating physiochemical properties, their preparation remains a great challenge. Here we report an easy and novel synthesis of 1D Pt nanostructures with controllable morphologies, through the combination of designer self-assembling $\mathrm{I}_{3} \mathrm{~K}$ and phage-displayed P7A peptides. The nanofibrils formed via $\mathrm{I}_{3} \mathrm{~K}$ self-assembly acted as template. Pt precursors $\left(\left(\mathrm{PtCl}_{4}\right)^{2-}\right.$ and $\left.\left(\mathrm{PtCl}_{6}\right)^{2-}\right)$ were immobilized by electrostatic interaction on the positively charged template surface and subsequent reduction led to the formation of $1 \mathrm{D} \mathrm{Pt}$ nanostructures. P7A was applied to tune the continuity of the Pt nanostructures. Here, the electrostatic repulsion between the deprotonated C-terminal carboxyl groups of P7A molecules was demonstrated to play a key role. We finally showed that continuous and ordered 1D Pt morphology had a significantly improved electrochemical performance for the hydrogen and methanol electro-oxidation in comparison with either $1 \mathrm{D}$ discrete $\mathrm{Pt}$ nanoparticle assemblies or isolated Pt nanoparticles.

P latinum (Pt) nanoparticles (NPs) are widely employed as electrocatalysts in fuel cells ${ }^{1}$. However, there are several obstacles associated with isolated nanoparticles, such as a large number of lattice boundaries, surface defect sites, interfaces between NPs and uncertainties associated with migration, aggregation and Ostwald ripening, all of which are detrimental to their catalytic performance and utilization efficiency. To address these issues, one-dimensional (1D) Pt nanostructures have recently been explored, and they exhibited improved catalytic activity, durability, and $\mathrm{CO}$ tolerance ${ }^{2-6}$. In fact, as a connection between nanometer-scale objects and the macro-scale world, the 1D anisotropic nanostructures possess some peculiar structural features and fascinating physicochemical properties, which are usually inaccessible to NPs and bulk materials ${ }^{7-10}$. However, the difficulties associated with the preparation of $1 \mathrm{D}$ metal nanostructures with well-controlled sizes, shapes, and composition have slowed down their advancement as compared with isolated isotropic nanostructures ${ }^{7-9}$.

Among documented strategies for achieving $1 \mathrm{D}$ inorganic growth, template-directed synthesis provides a good control over the dimensions and uniformity ${ }^{8}$. Due to their structural diversity, specific binding to metal ions, and biodegradability, self-assembled peptide nanostructures have been explored in recent years as promising templates for the fabrication of metal nanostructures ${ }^{11-16}$. For practical applications, an ideal peptide template should (1) be self-assembled from short peptides that can be synthesized on a large scale and (2) be well dispersed in aqueous solution to enable efficient and uniform immobilization of metal NPs onto the template surface under mild conditions ${ }^{10}$. However, the peptides reported so far for templating 1D Pt nanostructures are rather limited $^{4,6,17-19}$ and more importantly, they are either long peptides (e.g. insulin ${ }^{6}$ ) and even viral particles (e.g. tobacco mosaic virus ${ }^{4}$ ) or extremely hydrophobic ones that usually contain the core sequences of amyloid peptides (e.g. $\mathrm{FF}^{17,18}$ ). These peptides have shown poor morphological control over 1D Pt nanostructures. In contrast, de novo design of short peptides offers a range of advantages in the effective control of Pt nanostructure and function. To date, however, little progress has been made towards the development of easy, controllable and cost-effective preparation of $1 \mathrm{D}$ Pt nanostructures.

To exploit the main advantages of both easy synthesis and direct control of self-assembled nanostructures of short designed peptides, we recently synthesized an ultrashort surfactant-like peptide $\mathrm{I}_{3} \mathrm{~K}\left(\mathrm{Ac}-\mathrm{IIIK}-\mathrm{CONH}_{2}\right)$ that readily self-assembles into long and uniform nanofibrils in aqueous solution, driven by molecular amphiphilicity and $\beta$-sheet hydrogen bonding ${ }^{20,21}$. The $\mathrm{I}_{3} \mathrm{~K}$ nanofibrils show excellent aqueous dispersion at higher concentrations (more than $10 \mathrm{mM}$ ) without detectable precipitation after storage in water for several months under 


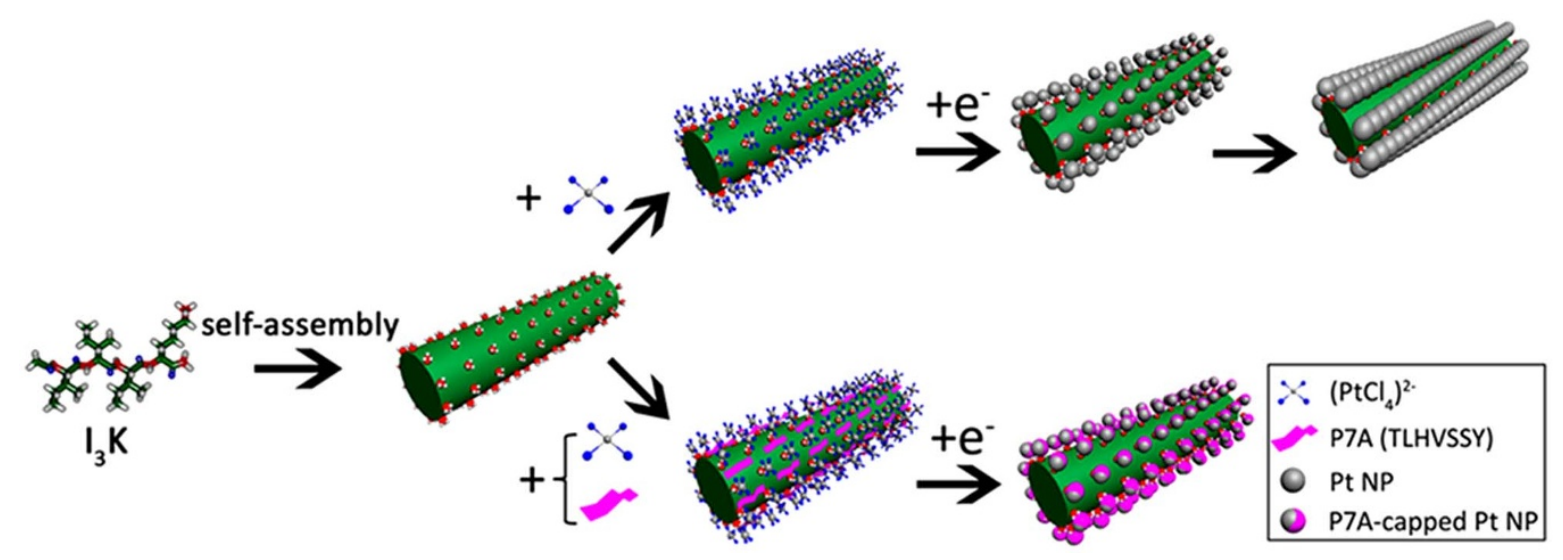

Figure 1 Schematic synthesis strategy of the 1D Pt nanostructures. The first step is $\mathrm{I}_{3} \mathrm{~K}$ self-assembly, leading to nanofibril formation (green column). The second step is anchoring of Pt NPs on the $\mathrm{I}_{3} \mathrm{~K}$ nanofibril surface in the presence or absence of P7A, leading to the formation of a well ordered array or a discrete distribution of the Pt nanostructures. P7A, a peptide capping agent, clearly alters the morphological patterns of the Pt nanostructures on the template surface.

ambient conditions, whereas, for example, amyloid fibrils readily precipitate in aqueous solution. In addition we have demonstrated that the $\mathrm{I}_{3} \mathrm{~K}$ assemblies template the formation of $1 \mathrm{D}$ silica nanostructures with controllable morphologies and dimensions $\mathrm{s}^{21-23}$. Based on these $\mathrm{I}_{3} \mathrm{~K}$ nanofibrils, we here report a simple templatedirected method to prepare 1D Pt nanostructures, and by coupling another short peptide P7A (TLHVSSY) that serves as a capping agent of the Pt NPs, the morphologies of the 1D Pt nanostructures on the $\mathrm{I}_{3} \mathrm{~K}$ template surface can be finely tuned, with the ability to be switched between ordered and discrete 1D Pt NP superstructures. Our 1D continuous Pt nanostructures exhibited significantly improved electrocatalytic performances over the existing NP based systems.

\section{Results}

Synthesis and characterization. As shown schematically in Fig. 1, the route consists of two consecutive steps, peptide self-assembly and the synthesis of the Pt nanostructures on the assembled template. After one-week incubation at $4 \mathrm{mM}$ in water (far above the peptide's critical aggregation concentration), $\mathrm{I}_{3} \mathrm{~K}$ self-assembles into stable fibrils with lengths of several $\mu \mathrm{m}$ and a width of $10.0 \pm 1.3 \mathrm{~nm}$ (Fig. 2). P7A is also a short peptide but selected through phage display technology, which specifically binds to the Pt crystal surface, showing good stabilization for small Pt NPs under $5 \mathrm{~nm}$ (Supplementary Fig. S1a) ${ }^{24,25}$. To obtain 1D Pt nanostructures, the aged $\mathrm{I}_{3} \mathrm{~K}$ stock solution was mixed firstly with a fresh aqueous solution containing P7A and $\mathrm{K}_{2} \mathrm{PtCl}_{4}$, followed by the addition of a fresh $\mathrm{NaBH}_{4}$ solution. The final concentrations of $\mathrm{I}_{3} \mathrm{~K}, \mathrm{P} 7 \mathrm{~A}$, $\mathrm{K}_{2} \mathrm{PtCl}_{4}$ and $\mathrm{NaBH}_{4}$ in the mixture were 2, 1, 1 and $1 \mathrm{mM}$, respectively. After reaction for $24 \mathrm{hr}$ at ambient temperature, the mixture became a black suspension. Transmission electron microscopy (TEM) imaging indicated the formation of $1 \mathrm{D}$ discrete Pt NP assemblies with a width of $9.4 \pm 1.2 \mathrm{~nm}$ (Fig. 3a and Supplementary Fig. S1b). The sizes of the assembled Pt NPs within such a $1 \mathrm{D}$ superstructure are $1.8 \pm 0.3 \mathrm{~nm}$, comparable to those of their free counterparts obtained without the template (Supplementary Fig. S1a). The edge-to-edge distance between the assembled Pt NPs is $0.7 \pm 0.2 \mathrm{~nm}$. High-resolution TEM (HRTEM) revealed a lattice spacing of $0.223 / 0.224 \mathrm{~nm}$, characteristic of the interplane spacing of Pt (111) planes (the bottom panel of Fig. 3a).

Similar synthesis in the absence of P7A generated 1D ordered continuous Pt NP assemblies with a width of $10.2 \pm 1.5 \mathrm{~nm}$ (Fig. $3 \mathrm{~b}$ and $3 \mathrm{c}$ and Supplementary Fig. S1c). Although the lateral interparticle spacing is still discernible, the longitudal fusion of NPs along the peptide template is highly evident. In spite of such morphological changes, the lattice spacing of $0.223 \mathrm{~nm}$ still dominates for the $1 \mathrm{D}$ continuous Pt NP assemblies (the bottom panel of Fig. 3b).

When the amount of P7A was low $(0.24 \mathrm{mM})$, NPs attached on the $\mathrm{I}_{3} \mathrm{~K}$ template surface were close packed and some interparticle fusion was still evident along the longitudal direction (Supplementary Fig. S1d). When the amount of P7A increased to $2 \mathrm{mM}$, Pt NP double and single helices (Fig. 3d) were formed. For the two superstructures, the edge-to-edge distance between Pt NPs along the helix is $1.1 \pm 0.2 \mathrm{~nm}$ and $1.6 \pm 0.5 \mathrm{~nm}$, respectively. Although the underlying mechanism associated with the formation of such helical superstructures remains elusive, it is likely to be associated with the twisting of $\beta$-sheets that comprise the peptide nanofibrils ${ }^{26}$. On the other hand, it is possible to make P7A stabilized Pt NPs separately from the template and then add them to the $\mathrm{I}_{3} \mathrm{~K}$ solution. In this situation, Pt NPs adsorbed discretely onto the $\mathrm{I}_{3} \mathrm{~K}$ nanofibrils, in a much looser arrangement than the 1D Pt nanostructures prepared as described above (Supplementary Fig. S2).

Mechanism. The $\mathrm{I}_{3} \mathrm{~K}$ template surface is rich in hydrophilic lysine residues and, in the case of silica nanostructures, the interfacial electrostatic attraction between the positively charged lysine residues and negatively charged silica precursors is the driving force for the templated synthesis ${ }^{21,22}$. In the present case (the solution $\mathrm{pH}$ was in the range of 6.0-9.0, depending on reaction time), we hypothesize that the formation of the $1 \mathrm{D} \mathrm{Pt}$ nanostructures is similarly driven by the electrostatic attraction, and proceeds with

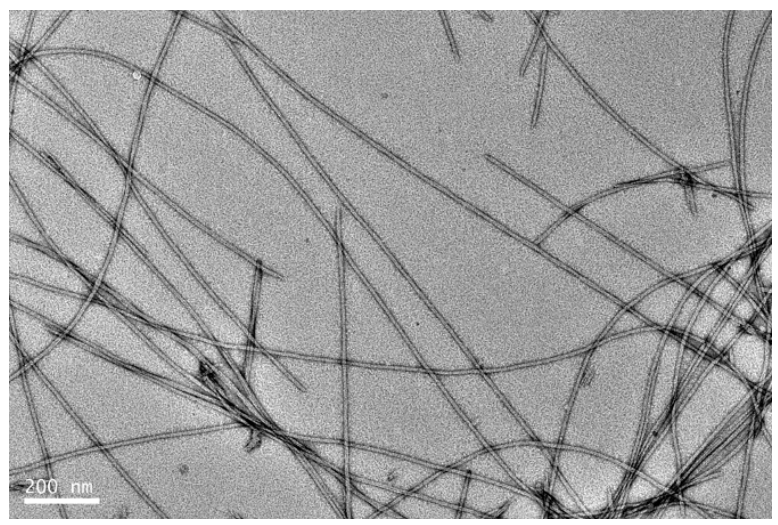

Figure $2 \mid$ TEM micrograph of $\mathrm{I}_{3} \mathrm{~K}$ nanofibrils. The peptide solution ( $4 \mathrm{mM}$ in water) was incubated for 1 week at $\mathrm{pH}$ of around 7 and the sample was negatively stained with $2 \%$ uranyl acetate before TEM imaging. 

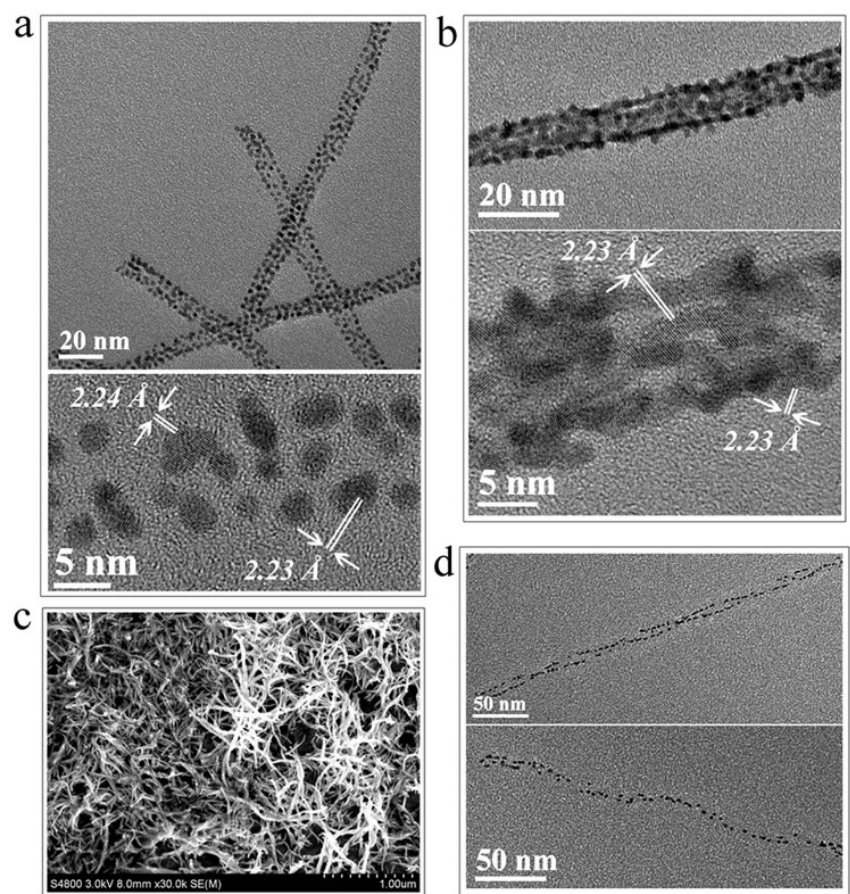

Figure 3 Structural characterization of 1D Pt nanostructures. (a) TEM (top) and HRTEM (bottom) images of 1D assemblies of discrete Pt NPs produced by reducing $\mathrm{K}_{2} \mathrm{PtCl}_{4}$ in the presence of $2 \mathrm{mM} \mathrm{I}_{3} \mathrm{~K}$ and $1 \mathrm{mM}$ P7A; (b) TEM (top) and HRTEM (bottom) images of 1D assemblies of continuous Pt NPs produced by reducing $\mathrm{K}_{2} \mathrm{PtCl}_{4}$ in the presence of $2 \mathrm{mM}$ $\mathrm{I}_{3} \mathrm{~K}$ but without P7A; (c) Scanning electron microscopy (SEM) image of 1D ordered continuous Pt NP assemblies; (d) TEM images of Pt NP double and single helices produced by reducing $\mathrm{K}_{2} \mathrm{PtCl}_{4}$ in the presence of $2 \mathrm{mM}$ $\mathrm{I}_{3} \mathrm{~K}$ and $2 \mathrm{mM}$ P7A.

the binding of the negatively charged $\left(\mathrm{PtCl}_{4}\right)^{2-}$ ions to the positively charged surface of the template, followed by the reduction of $\mathrm{Pt}$ (II) to Pt (0) and the nanocrystal growth.

To confirm this hypothesis, two comparative experiments were carried out. In the first one, we used the nanofibrils (Fig. 4a) selfassembled from negatively charged $\mathrm{I}_{3} \mathrm{D}$ (Ac-IIID-CONH$\left.{ }_{2}\right)$ instead of the $\mathrm{I}_{3} \mathrm{~K}$ nanofibrils as the template. Only random Pt NP aggregates were obtained, consistent with the result from the blank reaction without any additives (Fig. 4b). Subsequently, we substituted $\mathrm{K}_{2} \mathrm{PtCl}_{6}$ for $\mathrm{K}_{2} \mathrm{PtCl}_{4}$ as the precursor. $1 \mathrm{D}$ continuous Pt NP assemblies with a width of $13.6 \pm 0.9 \mathrm{~nm}$ formed (Fig. 4c). However, the faster reduction rate associated with $\left(\mathrm{PtCl}_{6}\right)^{2-}$ ions made this type of 1D Pt nanostructure much rougher.

Through its specific and strong binding to the Pt crystal surface, P7A probably favors the formation of ultrasmall Pt NPs and helps to ensure the complete dispersion of the resulting Pt NPs in water for several months ${ }^{24}$. To examine the stabilization mechanism of this type of aqueous colloidal dispersion, we adjusted the $\mathrm{pH}$ from around 7.0 to 2.0 and precipitation immediately followed, together with clear NP aggregates observable in TEM (Supplementary Fig. $\mathrm{S} 3 \mathrm{a})$. When the solution $\mathrm{pH}$ was reversed to 7.0 or higher values, the black precipitates redispersed well in water and the solution became clear again (Supplementary Fig. S3b). As the pKa of the Cterminal carboxyl group of the peptide is around 2.2, this indicates that the electrostatic repulsion between the deprotonated C-terminal carboxyl groups of the attached P7A molecules is responsible for the stability of the Pt NP aqueous solution. Consistent with this result, when we used the C-terminal capping of P7A (TLHVSSY-CONH${ }_{2}$ ) instead of the uncapped P7A, aggregation occurred during the very early stages of the reaction (Supplementary Fig. S3c). These results strongly suggest that the electrostatic repulsion between bound P7A is responsible for the formation of the $1 \mathrm{D}$ discrete Pt NP assemblies on the $\mathrm{I}_{3} \mathrm{~K}$ template and for the rather uniform interparticle spacing. Without the peptide, Pt NPs tend to fuse along the $\mathrm{I}_{3} \mathrm{~K}$ template, resulting in the formation of the well aligned and continuous $1 \mathrm{D} \mathrm{Pt}$ NP assemblies schematically shown in Fig. 1.

Electrochemical performance. To probe the structure-activity relationships of the various $\mathrm{Pt}$ nanostructures, we conducted electrochemical measurements on a CHI 660D electrochemical workstation. To remove residual precursors, the as-synthesized $\mathrm{Pt}$ nanostructures were centrifuged and the collected precipitates were redispersed in water. After repeating the treatment five times, the concentration of $\mathrm{Pt}$ in solution was determined by atomic absorbance spectroscopy. The resulting Pt nanostructure solutions were mixed with VXC-72R carbon black in a $1: 4$ weight ratio of $\mathrm{Pt}$ to $\mathrm{C}$ and sonicated for a while to obtain homogenous suspensions. The $\mathrm{Pt} / \mathrm{C}$ aqueous suspensions were dropped onto newly polished, cleaned glassy carbon electrodes (GCEs), dried and immobilized with Nafion solution. Cyclic voltammetry (CV) curves of hydrogen oxidation were recorded at ambient temperature in a $\mathrm{N}_{2}$-saturated $0.5 \mathrm{M} \mathrm{H}_{2} \mathrm{SO}_{4}$ solution at a scan rate of $50 \mathrm{mV} \mathrm{s}^{-1}$ for $1 \mathrm{D} \mathrm{Pt} \mathrm{NP}$ assemblies, isolated Pt NPs, and commercial Pt black. Note that the amounts of Pt loadings mounted on the working electrode (GCE) were $13.5 \pm 0.2 \mu \mathrm{g} \mathrm{cm}^{-2}$ in all cases. All CV curves display hydrogen adsorption and desorption regions $(-0.22$ to $0.15 \mathrm{~V}$ versus SCE (saturated calomel reference electrode)) and Pt surface oxide formation and reduction regions (0.15 to $1.15 \mathrm{~V})$, with representative ones given in Fig. 5a.

The specific electrochemical active surface area (ECSA) was calculated by the integration of the hydrogen desorption region (Fig. 5b). It is evident that 1D Pt nanostructures have higher specific ECSA values than isolated NPs (commercial Pt black and Pt NPs produced in the presence of $0.12 \mathrm{mM} \mathrm{P7A}$ ). For the various $1 \mathrm{D} \mathrm{Pt}$ nanostructures, the electrochemical activity is proportional to their a

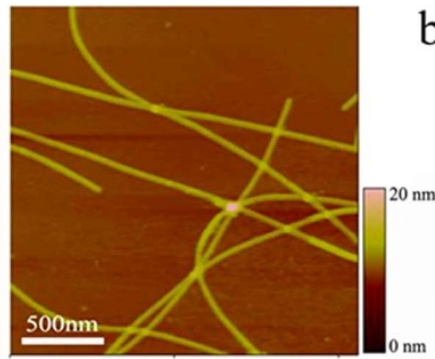

b

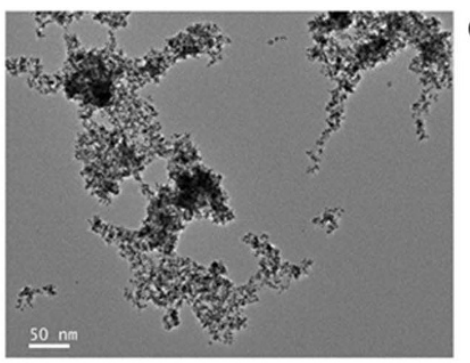

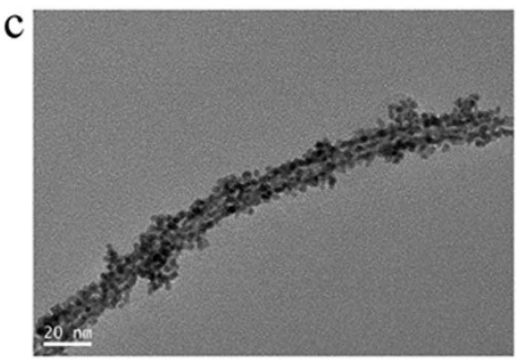

Figure $4 \mid$ Micrographs of $\mathrm{I}_{3} \mathrm{D}$ nanofibrils and the Pt NP assemblies produced in comparative experiments. (a) AFM image of $\mathrm{I}_{3} \mathrm{D}$ nanofibrils formed at $4 \mathrm{mM}$ in water after one-week incubation at $\mathrm{pH}$ of 7. (b) TEM image of Pt NP aggregates synthesized by reducing $\mathrm{K}_{2} \mathrm{PtCl}_{4}$ in the presence of $2 \mathrm{mM}^{2}$ $\mathrm{I}_{3} \mathrm{D}$ and $1 \mathrm{mM}$ P7A after reaction for $24 \mathrm{hr}$. (c) TEM image of $1 \mathrm{D}$ continuous Pt NP assemblies produced by reducing $\mathrm{K}_{2} \mathrm{PtCl}_{6}$ in the presence of 2 $\mathrm{mM} \mathrm{I}_{3} \mathrm{~K}$ but without P7A after $24 \mathrm{hr}$ reaction. 

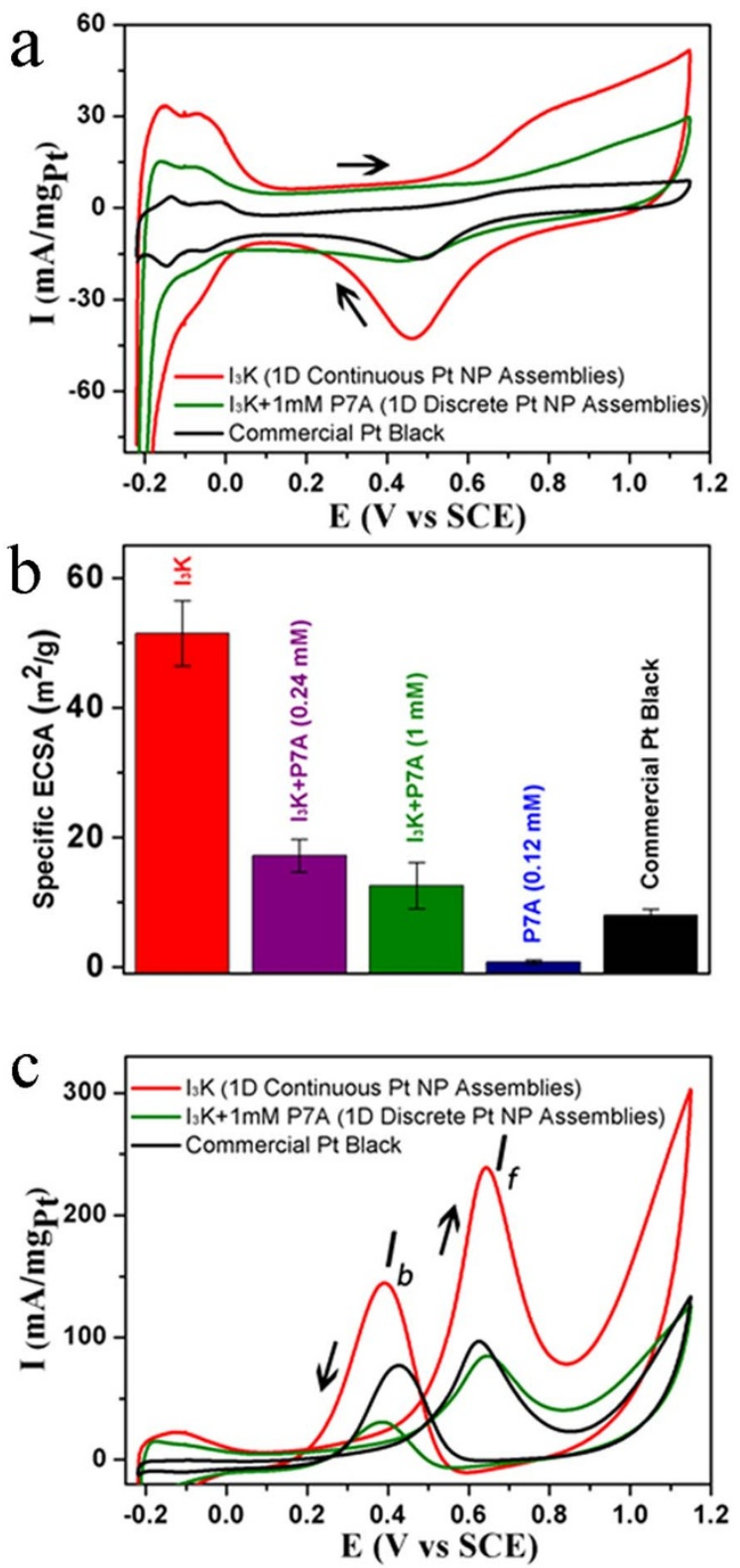

Figure 5 Comparison of electrocatalytic properties of different $\mathrm{Pt}$ nanostructures. (a) $\mathrm{CV}$ curves in a $\mathrm{N}_{2}$-saturated $0.5 \mathrm{M} \mathrm{H}_{2} \mathrm{SO}_{4}$ solution with a sweep rate of $50 \mathrm{mV} \mathrm{s}^{-1}$; the indicated Pt nanostructures include 1D continuous Pt NP assemblies synthesized in the presence of only $\mathrm{I}_{3} \mathrm{~K}$ (denoted as " $\mathrm{I}_{3} \mathrm{~K}$ "), $1 \mathrm{D}$ discrete Pt NP assemblies synthesized in the presence of $2 \mathrm{mMI}_{3} \mathrm{~K}$ and $1 \mathrm{mM}$ P7A (denoted as " $\mathrm{I}_{3} \mathrm{~K}+1 \mathrm{mM}$ P7A") and commercial Pt black. (b) Specific ECSAs; note that in this case, specific ECSAs of the 1D Pt NP nanostructure produced in the presence of $2 \mathrm{mM}$ $\mathrm{I}_{3} \mathrm{~K}$ and $0.24 \mathrm{mM}$ P7A and the isolated Pt NPs in the presence of $0.12 \mathrm{mM}$ P7A are also given for comparison. (c) CV curves in a $\mathrm{N}_{2}$-saturated $0.5 \mathrm{M}$ $\mathrm{H}_{2} \mathrm{SO}_{4}$ solution containing $1 \mathrm{M}$ methanol.

order and continuity along the axial direction. The 1D ordered and continuous Pt NP assemblies produced in the presence of only $\mathrm{I}_{3} \mathrm{~K}$ showed an exceptionally high specific ESCA of $51.5 \mathrm{~m}^{2} \mathrm{~g}^{-1}$ and the $1 \mathrm{D}$ discrete Pt NP assemblies (produced in the presence of the $\mathrm{I}_{3} \mathrm{~K}$ template and $1 \mathrm{mM} \mathrm{P7A}$ ) had a specific ESCA of $12.6 \mathrm{~m}^{2} \mathrm{~g}^{-1}$, which is slightly greater than that of the commercial Pt black of $8.0 \mathrm{~m}^{2} \mathrm{~g}^{-1}$. In contrast, the 1D Pt NP assemblies with limited continuity, which were produced in the presence of the $\mathrm{I}_{3} \mathrm{~K}$ template and $0.24 \mathrm{mM}$ P7A, displayed a specific ESCA of $17.2 \mathrm{~m}^{2} \mathrm{~g}^{-1}$.
CV curves for the methanol oxidation of various Pt nanostructures were also recorded under the same conditions except the electrolyte solution contained $0.5 \mathrm{M} \mathrm{H}_{2} \mathrm{SO}_{4}$ and $1 \mathrm{M} \mathrm{CH}_{3} \mathrm{OH}$. Note that the $\mathrm{Pt}$ loading was still at $13.5 \pm 0.2 \mu \mathrm{g} \mathrm{cm}^{-2}$ in this case. As shown in Fig. $5 c$, the two anodic current peaks in the forward and backward sweeps (around 0.64 and $0.4 \mathrm{~V}$ ) represent the methanol oxidation and the removal of the incompletely oxidized carbonaceous species from the Pt surface, respectively. Again, it is the $1 \mathrm{D}$ continuous Pt NP assemblies that display an exceptionally high activity for methanol oxidation, with a forward peak current $\left(\mathrm{I}_{\mathrm{f}}\right)$ of $239 \mathrm{~mA} \mathrm{mg} \mathrm{m}^{-1}$ at $0.64 \mathrm{~V}$, which is significantly greater than those of the $1 \mathrm{D}$ discrete Pt NP assemblies $\left(85 \mathrm{~mA} \mathrm{mg}^{-1}\right.$ at $\left.0.65 \mathrm{~V}\right)$ and Pt black $\left(97 \mathrm{~mA} \mathrm{mg}^{-1}\right.$ at $0.63 \mathrm{~V})$. Furthermore, the ratios of $\mathrm{I}_{\mathrm{f}} / \mathrm{I}_{\mathrm{b}}\left(\mathrm{I}_{\mathrm{b}}\right.$ : the backward peak current) for the $1 \mathrm{D}$ continuous and discrete $\mathrm{Pt} \mathrm{NP}$ assemblies and $\mathrm{Pt}$ black are about 1.6, 2.4, and 1.1, suggesting that the 1D Pt NP nanostructures have the better oxidation ability for the poisoning species (e.g. CO $)^{3,4,27}$.

For the 1D continuous Pt nanostructures, the significant improvements in available surface area, electrocatalytic activity and CO tolerance can be explained by the peculiar structural properties associated with 1D continuous morphology. Specifically, the continuous feature of NP assemblies obviously favors charge transfer by reducing the number of interfaces between $\mathrm{NPs}^{3-5}$. The $1 \mathrm{D}$ structural anisotropy not only reduces surface defects but also allows for the preferential display of certain crystal facets such as (100) and (111), favoring high methanol oxidation activity and CO tolerance $e^{5,6}$. The higher electric conductivity of the 1D continuous Pt NP assemblies was verified by the SEM characterization in which high resolution images could be readily obtained without gold coating (Fig. 3C). In contrast, it is hard to obtain clear SEM images without gold coating for the discrete Pt nanostructures, because of their limited electric conductivity. While this is not a quantitative measurement of the electrical conductivity, it strongly indicates the isolation of the particles in discrete structures.

\section{Discussion}

We have demonstrated a new and easy route to produce $1 \mathrm{D} \mathrm{Pt}$ nanostructures with controllable morphologies through the combination of designed $\mathrm{I}_{3} \mathrm{~K}$ and phage-displayed P7A peptides. The $\mathrm{I}_{3} \mathrm{~K}$ self-assembled nanofibrils function as a template and P7A serves as a capping agent to achieve switching between ordered and discrete 1D Pt NP superstructures. It was also demonstrated that double and single helical Pt NP assemblies can be fabricated at a higher P7A concentration of $2 \mathrm{mM}$. Benefitting from these special structural properties, the continuous and ordered 1D Pt morphology showed significantly improved electrochemical performance for the hydrogen and methanol electro-oxidation as compared to $1 \mathrm{D}$ discrete $\mathrm{Pt}$ NP assemblies and isolated Pt NPs. Its overall performance challenges that of the 1D continuous Pt nanostructures templated on insulin fibrils and TMV nanotubes ${ }^{4,6}$ in a number of respects including the low synthesis cost, ease of handling and clear structure-function relation of the short peptides. The present study provides a potential methodology for the large scale production of 1D Pt nanostructures with controllable morphologies and electrocatalytic properties. Detailed investigations on these 1D Pt nanostructures are underway for better control of morphology and systematic evaluation of their electrochemical performance as electrocatalysts for fuel cells.

\section{Methods}

Materials. Protected amino acids, coupling reagents, resins, cleavage reagents, and solvents for peptide synthesis were purchased from GL Biochem (Shanghai) Ltd. Potassium tetrachloroplatinate $\left(\mathrm{K}_{2} \mathrm{PtCl}_{4}\right)$ and hexachloroplatinate $\left(\mathrm{K}_{2} \mathrm{PtCl}_{6}\right)$ were obtained from Acros. All reagents were used as received except dichloromethane and $\mathrm{N}, \mathrm{N}$-dimethyl formamide that were redistilled prior to use. All water used was processed by a Millipore purification system with a minimum resistivity of $18.2 \mathrm{M} \Omega \cdot \mathrm{cm}$ 
Peptide synthesis and characterization. Ac-IIIK-CONH ${ }_{2}\left(\mathrm{I}_{3} \mathrm{~K}\right)$, TLHVSSY (P7A), Ac-IIID-CONH${ }_{2}\left(\mathrm{I}_{3} \mathrm{D}\right)$ and TLHVSSY-CONH${ }_{2}$ were synthesized from the $\mathrm{C}$ terminus to the $\mathrm{N}$ terminus on a CEM Liberty microwave synthesizer, based on the standard Fmoc solid phase synthesis strategy. The Rink amide MBHA resin and Wang resin were used to allow the C-terminus capped (amidated) and uncapped, respectively. The $\mathrm{N}$-terminus of $\mathrm{I}_{3} \mathrm{~K}$ was capped with acetic anhydride prior to cleavage from resin. Detailed synthesis and purification procedures have been described in our previous work ${ }^{20,21}$. The final products were subjected to mass spectrometry (MALDI-ToF) and reversed-phase HPLC analyses (Supplementary Fig. S4 and S5), indicating high purities (95\%).

Preparation of Pt nanostructures. $0.4 \mathrm{~mL}$ of $5 \mathrm{mM}$ P7A aqueous stock solution, $0.2 \mathrm{~mL}$ of freshly prepared $10 \mathrm{mM} \mathrm{K}_{2} \mathrm{PtCl}_{4}$ in water and $0.35 \mathrm{~mL}$ of water were added into $1 \mathrm{~mL}$ of $4 \mathrm{mM} \mathrm{I}_{3} \mathrm{~K}$ well-aged aqueous stock solution ( 1 week, $\mathrm{pH}$ of $\sim 7$ ), followed by addition of $0.05 \mathrm{~mL}$ of freshly prepared $40 \mathrm{mM} \mathrm{NaBH}_{4}$ in water. The final concentrations of $\mathrm{I}_{3} \mathrm{~K}, \mathrm{P} 7 \mathrm{~A}, \mathrm{~K}_{2} \mathrm{PtCl}_{4}$ and $\mathrm{NaBH}_{4}$ were $2,1,1$ and $1 \mathrm{mM}$, respectively. The mixture was sealed tightly in a plastic vial and stirred strongly for a while, then left to stand for $24 \mathrm{~h}$ at room temperature to insure complete reaction. To get different morphologies of $1 \mathrm{D}$ Pt nanostructures, the final concentration of P7A in the reaction mixture was adjusted to be $2,0.24$, and $0 \mathrm{mM}$, respectively, with other reaction conditions being the same. For comparative experiments, we used $\mathrm{I}_{3} \mathrm{D}$ instead of $\mathrm{I}_{3} \mathrm{~K}$ or $\mathrm{K}_{2} \mathrm{PtCl}_{6}$ instead of $\mathrm{K}_{2} \mathrm{PtCl}_{4}$, also with other reaction conditions unchanged.

For isolated Pt NPs, the reaction was performed in the presence of $0.12 \mathrm{mM} \mathrm{P7A}$ or $\mathrm{C}$-terminal capped P7A and in the absence of $\mathrm{I}_{3} \mathrm{~K}$, with other reaction condition being the same as above.

Instrumental characterization of Pt nanostructures. For TEM characterization, $30 \mu \mathrm{L}$ of the above reaction solutions were placed on 300-mesh copper grids covered with carbon-stabilized Formvar film, followed by quick drying with filter paper. The grids were then observed with a JEOL JEM 2100 UHR TEM operating at $200 \mathrm{kV}$. For SEM characterization, $20 \mu \mathrm{L}$ of the reaction solutions were placed on a carefully cleaned SEM stub, vacuum dried at room temperature and then subjected to imaging with a Hitachi S-4800 field emission SEM at $10 \mathrm{kV}$.

Electrochemical experiments. CV measurements were carried out with a CHI 660D electrochemical workstation (ChenHua, Shanghai) in a standard three-electrode cell consisting of a glassy carbon electrode (GCE) with a diameter of $3 \mathrm{~mm}$ as the working electrode, a saturated calomel reference electrode (SCE) and a Pt wire counter electrode.

To remove residual precursors, the above reaction solutions were centrifuged at $10000 \mathrm{rpm}$ for $6 \mathrm{~min}$ and the collected precipitates were redispersed in $1 \mathrm{~mL}$ water through sonication. After repeating this treatment five times, the concentration of $\mathrm{Pt}$ in solution was determined with an Analytic Jena ContrAA 700 high-resolution atomic absorbance spectrometer. The purified Pt solutions were mixed with VXC$72 \mathrm{R}$ carbon black in a $1: 4$ weight ratio of $\mathrm{Pt}$ to $\mathrm{C}$ and sonicated for a while to obtain homogenous $\mathrm{Pt} / \mathrm{C}$ suspensions.

Before Pt loading, the GCE was polished successively with $1.0,0.3$, and $0.05 \mu \mathrm{m}$ $\mathrm{Al}_{2} \mathrm{O}_{3}$ powders to a mirror finish, followed by successive sonication in ethanol, acetone, $50 \%(\mathrm{v} / \mathrm{v})$ nitric acid solution, and water. After electrochemical cleaning in $0.5 \mathrm{M} \mathrm{H}_{2} \mathrm{SO}_{4}$ aqueous solution and copious rinsing with water, the electrode was dried with nitrogen purging.

$4 \mu \mathrm{L}$ of the $\mathrm{Pt} / \mathrm{C}$ aqueous suspensions were dropped onto newly polished, cleaned glassy carbon electrodes (GCEs) and dried with an infrared lamp. To reach immobilization, $10 \mu \mathrm{L}$ of Nafion ethanol solution ( $0.1 \mathrm{wt} \%$, DuPont) was then dropped on these GCEs and air dried. The loading amounts of Pt were fixed at $13.5 \pm$ $0.2 \mu \mathrm{g} \mathrm{cm}^{-2}$ for all Pt nanostructures.

The electrodes were immersed in $10 \mathrm{ml} \mathrm{N}_{2}$-saturated $0.5 \mathrm{M} \mathrm{H}_{2} \mathrm{SO}_{4}$ solution, and the potential was scanned from -0.22 to $1.15 \mathrm{~V}$ at a scan rate of $50 \mathrm{mV} \mathrm{s}^{-1}$ with a sample interval of $0.001 \mathrm{~V}$ to obtain the $\mathrm{CV}$ curves of hydrogen oxidation. The $\mathrm{CV}$ curves of methanol oxidation reaction (MOR) were recorded in $10 \mathrm{ml}$ nitrogensaturated solution containing $0.5 \mathrm{M} \mathrm{H}_{2} \mathrm{SO}_{4}$ and $1 \mathrm{M}$ methanol. Note that 10 cycles were firstly performed and the 11th cycle was typically used for attaining reproducible signals in both cases.

After subscribing the double-layer current, the hydrogen desorption region $(-0.2 \sim 0.15 \mathrm{~V})$ of the $\mathrm{CV}$ curves of hydrogen oxidation was integrated to estimate the electrochemical active surface area (ECSA), according to the following formulas:

$$
Q_{H}=\frac{1}{v} \int_{-0.2}^{0.15}\left(I-I_{d l}\right) d E
$$

Where $Q_{H}$ is the total charge; $I$ and $I_{d l}$ are the current and double-layer current, respectively; $\mathrm{E}$ is the potential (versus $\mathrm{SCE}$ ); and $v$ is the sweeping rate $\left(50 \mathrm{mV} \mathrm{s}^{-1}\right)$. The specific ECSA was calculated assuming:

$$
E C S A=\frac{Q_{H}}{\theta_{m}}
$$

$$
\text { specific ECSA }=\frac{E C S A}{m}
$$

where $\theta_{m}$ is the electric charge density for hydrogen adsorption and as a constant $\left(210 \mu \mathrm{C} \mathrm{cm}^{-2}\right), m$ is the loading amount of Pt.
1. Steel, B. C. H. \& Heinzel, A. Materials for fuel-cell technologies. Nature 414, 345-352 (2001).

2. Chen, Z., Waje, M., Li, W. \& Yan, Y. Supportless Pt and PtPd nanotubes as electrocatalysts for oxygen-reduction reactions. Angew. Chem. Int. Ed. 46, 4060-4063 (2007).

3. Choi, S. M., Kim, J. H., Jung, J. Y., Yoon, E. Y. \& Kim, W. B. Pt nanowires prepared via a polymer template method: its promise toward high Pt-loaded electrocatalysts for methanol oxidation. Electrochim. Acta 53, 5804-5811 (2008).

4. Górzny, M. Ł., Walton, A. S. \& Evans, S. D. Synthesis of high-surface-area platinum nanotubes using a viral template. Adv. Funct. Mater. 20, 1295-1300 (2010).

5. Koenigsmann, C. \& Wong, S. S. One dimensional noble metal electrocatalysts: a promising structural paradigm for direct methanol fuel cells. Energy Environ. Sci. 4, 1161-1176 (2011).

6. Zhang, L., Li, N., Gao, F., Hou, L. \& Xu, Z. Insulin amyloid fibrils: an excellent platform for controlled synthesis of ultrathin superlong platinum nanowires with high electrocatalytic activity. J. Am. Chem. Soc. 134, 11326-11329 (2012).

7. Xia, Y. \& Yang, P. Chemistry and physics of nanowires. Adv. Mater. 13, 351-352 (2003).

8. Xia, Y. et al. One-dimensional nanostructures: synthesis, characterization, and applications. Adv. Mater. 15, 353-388 (2003).

9. Tang, Z. \& Kotov, N. A. One-dimensional assemblies of nanoparticles preparation, properties, and promise. Adv. Mater. 17, 951-962 (2005).

10. Liang, H. W., Liu, J. W., Qian, H. S. \& Yu, S. H. Multiplex templating process in one-dimensional nanoscale: controllable synthesis, macroscopic assemblies, and applications. Acc. Chem. Res. 46, 1450-1461 (2013).

11. Gao, X. \& Matsui, H. Peptide-based nanotubes and their applications in bionanotechnology. Adv. Mater. 17, 2037-2050 (2005).

12. Gazit, E. Use of biomolecular templates for the fabrication of metal nanowires. FEBS J. 274, 317-322 (2007).

13. Dickerson, M. B., Sandhage, K. H. \& Naik, R. R. Protein- and peptide-directed syntheses of inorganic materials. Chem. Rev. 108, 4935-4978 (2008).

14. Chen, C. L. \& Rosi, N. L. Peptide-based method for the preparation of nanostructured inorganic materials. Angew. Chem. Int. Ed. 49, 1924-1942 (2010).

15. Yan, X., Blacklock, J., Li, J. \& Möhwald, H. One-pot synthesis of polypeptide-gold nanoconjugates for in vitro gene transfection. ACS Nano 6, 111-117 (2012).

16. Yan, X., Li, J. \& Möhwald, H. Templating assembly of multifunctional hybrid colloidal spheres. Adv. Mater. 24, 2663-2667 (2012).

17. Song, Y. et al. Synthesis of peptide-nanotube platinum-nanoparticle composites. Chem. Comm. 1044-1045 (2004).

18. Biswas, K. \& Rao, C. N. R. Nanostructured peptide fibrils formed at the organicaqueous interface and their use as templates to prepare inorganic nanostructures. ACS Appl. Mater. Interface 1, 811-815 (2009).

19. Kasotakis, E. et al. Design of metal-binding sites onto self-assembled peptide fibrils. Biopolymer (Pept. Sci.) 92, 164-172 (2009).

20. Han, S. et al. Self-assembly of short peptide amphiphiles: the cooperative effect of hydrophobic interaction and hydrogen bonding. Chem. Eur. J. 17, 13095-13102 (2011).

21. Xu, H. et al. Twisted nanotubes formation from ultrashort amphiphilic peptide $\mathrm{I}_{3} \mathrm{~K}$ and their templating for the fabrication of silica nanotubes. Chem. Mater. 22, 5165-5175 (2010).

22. Wang, S. et al. Mechanistic process underlying biomimetic synthesis of silica nanotubes from self-assembled ultrashort peptide templates. Chem. Mater. 23, 2466-2474 (2011).

23. Wang, S. et al. Biomimetic synthesis of silica nanostructures with controllable morphologies and sizes through tuning interfacial interactions. Chem. Comm. 48, 9415-9417 (2012).

24. Li, Y., Whyburn, G. P. \& Huang, Y. Specific peptide regulated synthesis of ultrasmall platinum nanocrystals. J. Am. Chem. Soc. 131, 15998-15999 (2009).

25. Li, Y. \& Huang, Y. Morphology-controlled synthesis of platinum nanocrystals with specific peptides. Adv. Mater. 22, 1-5 (2010).

26. Aggeli, A. et al. Hierarchical self-assembly of chiral rod-like molecules as a model for peptide $\beta$-sheet tapes, ribbons, fibrils, and fibers. Proc. Natl. Acad. Sci. USA 98, 11857-11862 (2001).

27. Chen, A. \& Holt-Hindle, P. Platinum-based nanostructured materials: synthesis, properties, and applications. Chem. Rev. 110, 3767-3804 (2010).

\section{Acknowledgements}

The authors are grateful for the National Natural Science Foundation of China (21033005 and 21076231), the Natural Science Funds of Shandong Province of China (JQ201105 and ZR2010BQ028), and the UK Engineering and Physical Sciences Research Council (EPSRC). H.X. acknowledges the support by Program for New Century Excellent Talents in University (NCET-11-0735).

\section{Author contributions}

K.T. and J.W. contributed equally to this work. H.X., J.W. and J.L. conceived and designed the experiments; K.T., J.W., Y.L. and D.X. performed the experiments and analyzed the data. H.X., J.L. and H.S. wrote the manuscript. All authors discussed and commented on the manuscript. 


\section{Additional information}

Supplementary information accompanies this paper at http://www.nature.com/ scientificreports

Competing financial interests: The authors declare no competing financial interests.
How to cite this article: Tao, K. et al. Short peptide-directed synthesis of one-dimensional platinum nanostructures with controllable morphologies. Sci. Rep. 3, 2565; DOI:10.1038/ srep02565 (2013)

(c) (1) (5) This work is licensed under a Creative Commons Attribution-

con ${ }_{\mathrm{Br}} \mathrm{NC}$ SA NonCommercial-ShareAlike 3.0 Unported license. To view a copy of this license, visit http://creativecommons.org/licenses/by-nc-sa/3.0 